\title{
SISTEMAS DE PAGOS VARIABLES Y REPRESENTACIÓN SINDICAL EN EMPRESAS MULTINACIONALES DE ARGENTINA
}

Sistemas de pagamentos variáveis e representantes sindicais em empresas multinacionais na Argentina

Variable payment systems and union representation in multinational companies in Argentina

Systèmes de paiements variables et les représentants syndicaux dans les entreprises multinationales en Argentine

Marcelo Delfini ${ }^{1}$

Doutor em Ciências Sociais - Universidade de Buenos Aires. Investigador CONICET. Docente de carrera de Relaciones del Trabajo, UBA

Alejandra Quadrana

Licenciada em Sociologia - Universidad de Buenos Aires. Becaria doctoral CONICET com sede no Instituto de Industria da Universidade Nacional de General Sarmiento

Ignacio Cretini ${ }^{3}$

Licenciado em Economia - Universidade de Buenos Aires. Becario doctoral CONICET com sede no Centro de Investigações e Transferência Golfo San Jorge

\section{RESUMEN}

En los últimos años las empresas han desarrollado un conjunto de transformaciones en materia de Gestión de la Fuerza de Trabajo procurando establecer lógicas de diferenciación salarial tendientes a individualizar las relaciones laborales. En este marco el artículo tiene como objetivo analizar los procesos de individualización salarial y el nivel de penetración sindical en empresas multinacionales de Argentina buscando determinar como se relacionan estos dos indicadores. Para analizar los sistemas de pagos variables, se toman en consideración el alcance y profundidad que adquieren las evaluaciones de desempeño y las partes variables que conforman el salario. El grado de penetración de los sindicatos se observa considerando la presencia sindical en los espacio s de trabajo y el nivel de afiliación. Junto a ello se busca establecer las diferencias existentes en torno a variables como el sector de actividad y el origen del capital de las empresas. Se avanzó en un estudio sobre filiales instaladas en el país mediante un abordaje cualitativo, que comprende entrevistas semiestructuradas a gerentes de recursos humanos.

Palabras clave: Multinacionales; Sistemas de pagos variables; Sindicatos; Relaciones laborales.

\section{RESUMO}

Nos últimos anos, as empresas desenvolveram um conjunto de transformações no domínio da Gestão da Força de Trabalho, buscando estabelecer lógicas de diferenciação salarial destinadas a individualizar as relações laborais. Neste contexto, o artigo tem como objetivo analisar os processos de individualização dos salários e o nível de inserção dos sindicatos em empresas multinacionais na Argentina, buscando determinar como esses dois

1 mdelfini@conicet.gov.ar

2 alequadrana@gmail.com

3 ignaciocretini@gmail.com 
indicadores se relacionam. Para analisar os sistemas de pagamentos variáveis, levaremos em consideração o alcance e a profundidade que adquire as avaliações de desempenho e as partes variáveis que compõem o salário. O grau de inserção dos sindicatos é vis to considerando a presença dos sindicatos nos espaços de trabalho e no nível de afiliação. Além disso o artigo busca es tabelecer as diferenças que existem em torno de variáveis como o setor de atividade e a origem do capital da empresa. Foi avançado em um estudo sobre subsidiárias instaladas no país através de uma abordagem qualitativa, que inclui entrevistas semiestruturadas com gestores de recursos humanos.

Palavras chave: multinacionais; sistemas de pagamento variáveis; sindicatos; relações industriais.

\begin{abstract}
In the last years companies have developed a set of transformations in the field of Work Force Management trying to establish logics of salary differentiation tending to individualize labor relations. In this context the article aims to analyze the processes of wage individualization and the level of union penetration in multinational companies in Argentina, trying to determine how these two indicators are related. To analyze the variable payment systems, the scope and depth of the performance evaluations and the variable parts that make up the salary are taken into account. The degree of penetration of the unions is observed considering the union presence in workspaces and the level of affiliation. In addition, it seeks to establish the existing differences around variables such as the sector of activity and the origin of capital of companies. The study focuses on subsidiaries installed in the country through a qualitative approach, comprising semi-structured interviews with human resources managers.
\end{abstract}

Key words: Multinationals; Variable payment systems; Union; Industrial relations.

\title{
RESUMÈ
}

Ces dernières années, les entreprises ont développé un ensemble de transformations dans le domaine de la Gestion de la Force de Travail, cherchant à établir des logiques de différenciation salariale visant à individualiser les relations de travail. Dans ce contexte, l'article vise à analyser les processus d'individualisation des salaires et le niveau de pénétration des syndicats dans les entreprises multinationales en Argentine, en cherchant à déterminer comment ces deux indicateurs se rapportent. Pour analyser des systèmes de paiement variables, la portée et la profondeur des évaluations de rendement et les parties variables qui comportent le salaire sont prises en considération. Le degré de pénétration des syndicats est vu en considérant la présence syndicale dans les espaces de travail et le niveau d'affiliation. En outre, il cherche à établir les différences qui existent autour des variables telles que le secteur d'activité et l'origine du capital de la société. Il a été avancé dans une étude sur les filiales installées dans le pays par une approche qualitative, qui comprend des entretiens semi-structurés avec les gestionnaires de ressources humaines.

Mots Clés: Multinationales; systèmes de paiement variable; syndicats; relations de travail.

\section{INTRODUCCIÓN}

El proceso de globalización tuvo como correlato central el incremento y preponderancia de las empresas multinacionales (EMN) y el aumento de sus filiales en otros países, lo que supuso la adaptación de instituciones, sistemas políticos y prácticas sociales de las naciones receptoras a las necesidades de acumulación de aquellas (Aronskind, 2015). Sklair (2003) sostiene que el funcionamiento del sistema global se desarrolla a partir de la fuerza que tienen las prácticas transnacionales aplicadas por las EMN, a la vez que son estas prácticas las que definen al capitalismo global en las últimas décadas, abandonando la mirada estadocéntrica. En este sentido, no habría Estados hegemónicos que explotan a otros sino el desarrollo de prácticas trasnacionales que pueden explotar o facilitar el desarrollo de los países. De esta forma, las EMN aparecen como actores centrales para el desarrollo de nuevas estrategias productivas y laborales, introduciendo nuevas prácticas en el empleo y las relaciones laborales en el país de instalación por medio de sus filiales con el fin de homogeneizar su operatoria. La hipótesis de la mayor parte de esta literatura indica que las EMN introducen un conjunto de prácticas en materia de relaciones laborales, sobre todo aquellas vinculadas a 
gestión de la fuerza de trabajo (GFT) con fuerte impacto sobre los trabajadores y en las estrategias de las organizaciones sindicales (Antenas Collderram, 2008 y (Léonard, Pulignano, Lamare y Edwards, 2014).

A partir de mediados de la década del '70, en el marco de la crisis del modelo fordista de producción, las empresas emprendieron un camino tendiente a modificar las relaciones laborales, a desvincular al trabajador de la representación gremial para debilitar a los sindicatos y a romper las solidaridades generadas en los espacios de trabajo. Las estrategias puestas en juego por las empresas para llevar adelante este proceso de transformación comenzaron con la división de las empresas en múltiples unidades productivas, un proceso de tercerización que condujo a heterogeneizar los colectivos laborales. Este proceso se unió a la división de los trabajadores, a partir de distintas formas contractuales, entre un núcleo estable y una periferia precaria que segmentó más el contenido colectivo de las relaciones laborales (Delfini, 2011; Delfini y Roitter, 2007). A estas prácticas, se incorporaron nuevas formas de gestión de la fuerza de trabajo que caen bajo la denominación de "gestión de recursos humanos" y que buscan generar una subjetividad del trabajador tendiente a estructurar solidaridades cuyo marco de referencia sea la empresa y que sean llevadas adelante en ese espacio.

En este contexto y en el marco de la extensión y transferencias de prácticas de GFT, se encuentran los Sistemas de Pagos Variables (SPV), algunos de los cuales avanzan en procesos de individualización salarial que buscan romper con el contenido colectivo que encarnan las organizaciones sindicales en torno a la negociación salarial. En este sentido, estas nuevas prácticas van desde formas colectivas de fijación salarial

\footnotetext{
${ }^{4}$ Si bien el fenómeno de los SPV no es exclusivo de las EMN, tomamos sus filiales como objeto de estudio para nuestro análisis en el marco del proyecto de investigación PICT 2013-0931
}

centralizada en las relaciones entre empleadores y sindicatos a fijaciones salariales más fragmentadas e individualizadas.

La relevancia de tomar a las filiales de EMN en Argentina como objeto de estudio está dada por la innegable influe ncia que tienen estas firmas en la economía, producción, organización del trabajo, empleo y relaciones laborales, que trasciende su ámbito específico de inserción, impactando sobre otros agentes e instituciones. Esta relevancia se ve corroborada en el fuerte proceso de extranjerización productiva de la economía argentina, como resultado de los crecientes flujos de inversión extranjera directa (IED). En este contexto, el presente artículo tiene como objetivos principales i) analizar el desarrollo de los SPV en las filiales argentinas de $\mathrm{EMN}^{4}$, ii) observar el nivel de penetración sindical en las empresas y iii) establecer la relación que hay entre estas dos dimensiones en virtud de poder determinar el desarrollo de procesos de individualización salarial.

Para comprender y analizar las prácticas vinculadas a las relaciones laborales en EMN de Argentina, avanzamos en un estudio sobre las filiales instaladas en el país, mediante una metodología cualitativa de abordaje, que comprende entrevistas realizadas a gerentes $y$ empleados del área de recursos humanos de las firmas seleccionadas. Dado que el país de origen de las EMN y el sector de actividad son elementos centrales al momento de explicar la construcción de estrategias empresarias, para ello se analizarán firmas de la industria y de servicios, diferenciando entre las empresas cuya casa matriz se encuentra en EE.UU y aquellas pertenecientes a Europa.

El artículo se encuentra organizado en una serie de apartados que buscan dar cuenta en su integración de los objetivos

"Empresas Multinacionales: Gestión de la fuerza de trabajo y respuestas sindicales 2003-2013", financiado por el Ministerio de Ciencia, Tecnología e Innovación Productiva de la Nación. 
propuestos. Así, en el primer apartado se presentan algunos de los debates y análisis en torno a las estrategias de la GFT y hacia los sindicatos que utilizan las EMN. En el segundo, se pone de manifiesto la discusión en torno a los SPV y las lógicas sindicales que se desenvuelven en las empresas. Posteriormente se presenta brevemente la importancia de las EMN en la estructura productiva argentina, para contextualizar luego las lógicas de fijación salarial en el marco del sistema de relaciones laborales. En el apartado cuatro se presenta las formas de abordaje metodológico y características de las empresas. Luego, se avanza en función de los datos obtenidos y posteriormente se presentan las conclusiones del este análisis.

\section{La individualización de las relaciones laborales y sindicatos en el marco de las estrategias de las EMN}

En los últimos años, los análisis sobre las EMN y más específicamente sobre la IED han tomado como punto de partida los estudios de Dunning (1994) sobre las estrategias de inversión de las firmas, quien distingue entre cuatro motivaciones que conducen a 1) la búsqueda de recursos naturales: explotar recursos naturales en terceros países; 2) la búsqueda de mercados: producir $\mathrm{y}$ vender productos en mercados locales o regionales; 3) la búsqueda de eficiencia: producir a bajo costo para exportar a otros mercados, o 4) la búsqueda de activos estratégicos: tener acceso a activos, como el conocimiento, la tecnología de punta o los recursos humanos calificados.

Partiendo de la idea de que la empresa multinacional es una configuración estratégica de control en continuo proceso de cambio, que combina lo local y lo global (Hernández Romo, 2014), se llevan adelante lo que denominamos "estrategias de segundo orden", que son aquellas a través de las cuales las EMN buscan sostener o aumentar la rentabilidad del negocio a nivel global, implementando prácticas en las filiales que generen las condiciones de posibilidad para el incremento de la productividad. En este sentido aparece como clave la GFT, la cual debe entenderse como el conjunto de prácticas que se desarrollan en las empresas para asegurar el funcionamiento productivo. Estas tienen que ver con la organización del proceso de trabajo y los dispositivos generados para aumentar el rendimiento de la fuerza laboral. En este sentido se sostiene que las prácticas de GFT en EMN están dirigidas a "reculturizar" a los trabajadores, atenuando y mediatizando el poder y la influencia de la representación sindical. Entre otras cosas, el aumento de los costos laborales, la protección de los trabajadores, la menor flexibilidad y sensibilidad al cambio y un clima antagónico entre la empresa y los trabajadores serían los factores que impulsarían a las EMN a desestructurar el poder sindical en las firmas (Flood y Toner, 1997).

En relación a ello, hacia principios de los años '80 se comenzaron a desarrollar nuevas formas de GFT cuya tendencia principal fue la introducción de prácticas de individualización de las relaciones entre trabajadores y empleadores. A decir de Boltanski y Chiapello (2002), se pone en juego toda una sofisticada panoplia de "herramientas de relaciones humanas", las cuales buscan generar una subjetividad del trabajador tendiente a estructurar solidaridades que se enmarcan y desarrollan en la empresa. Así, las nuevas prácticas fueron modificando los sistemas jerárquicos, característicos del fordismo, sustituyéndolos por mecanismos de "horizontalización" que buscaron difund ir formas de control basadas en el autocontrol y la responsabilidad de los trabajadores, relegando aún más la acción sindical.

Avanzando sobre el tema de las relaciones laborales y la presencia sindical en las EMN, una primera aproximación al anális is de las prácticas hacia los sindicatos indica la necesidad de observar las motivaciones que conducen a la empresa a 
establecer estrategias hacia este actor. Esta problemática se intentó abordar desde la perspectiva de la racionalidad limitada (Cooke, 2003), la cual asume que las firmas multinacionales tratan de optimizar la rentabilidad y así obtener un mayor rendimiento de la fuerza de trabajo, mientras que los sindicatos tratan de actuar de manera de maximizar los beneficios de los trabajadores. Así, los gerentes evalúan la opción de evadir la presencia sindical o reconocerla con criterios relacionados al impacto en el rendimiento de la operativa de la filial. Sin embargo, la decisión puede estar condicionada por el sistema de relaciones laborales del país de instalación, sus normas, sus leyes y su historia.

En sintonía con las preocupaciones referidas, desde diferentes perspectivas se han analizado las relaciones laborales y las estrategias empresarias hacia los sindicatos, dando lugar a numerosos estudios que han expuesto las prácticas hacia los sindicatos en los diferentes niveles que integran las relaciones laborales (Delfini, 2011) ${ }^{5}$. Algunos se concentraron en la observación de las condiciones brindadas por el sistema de relaciones laborales en un nivel macro, estableciendo el efecto de las leyes y normas a favor de las prácticas anti sindicales, siendo utilizadas por los empresarios en los espacios de trabajo (Gall, 2009). En este marco se pueden ubicar los análisis que determinan el desarrollo de ciertos márgenes de libertad donde las empresas tienen capacidad para introducir ciertas lógicas de acción. De esta manera, estudios sobre la presencia de firmas de EEUU e Inglaterra en Alemania,

5 Consideramos a las relaciones laborales constituidas por tres niveles analíticos: El nivel "micro" que considera las relaciones entabladas en el espacio de trabajo entre los empleadores, los trabajadores y los representantes gremiales. A su vez, en este nivel, las relaciones laborales refieren a la forma de gestión, a la organización del proceso productivo y a la relación entre los empleadores y los representantes de los trabajadores. El segundo nivel "meso" se encuentra vinculado con el ámbito de las actividades productivas y hace referencia a actores como sindicatos sectoriales, cámaras empresarias y cuya regulación está vinculada a la fortaleza sindical en los espacios de trabajo, muestran la existencia de cierto margen de maniobra para introducir prácticas hacia los sindicatos vinculados a los contextos institucionales de la casa matriz (Royle, 1998 y Tempel, 2001).

Por otra parte se han llevado adelante una serie de análisis sobre las estrategias hacia los sindicatos que han puesto de relieve la integración de los diferentes niveles. En este sentido, tanto los factores macro, que generan las condiciones de posibilidad para el desarrollo de las prácticas anti sindicales, como los elementos relativos al interior de la firma, vinculados a las prácticas de gestión, inciden en la desvinculación de los trabajadores respecto de los sindicatos, o bien no posibilitan la intervención de éstos últimos en los ámbitos laborales. Estos estudios ponen en evidencia el conjunto de normas que conducen a una pérdida de poder de los sindicatos y muestran las estrategias anti sindicales desarrolladas a partir de los procesos de tercerización, cierre de empresas, contratos diferenciales para los empleados, políticas agresivas hacia los sindicatos, políticas de selección y reclutamiento de personal y el impedimento de incorporar personal con trayectoria ligada a las organizaciones sindicales (Cooper, Ellen, Briggs, y Van de Broek, 2009).

Muchos de los estudios sobre la evasión sindical en las empresas hacen hincapié en las prácticas desarrolladas por las empresas norteamericanas, el contexto de su desarrollo en el marco de instituciones

\footnotetext{
sus relaciones. En esta instancia se genera una especie de coordinación entre la multiplicidad de unidades productivas que integran cada actividad. Por último, el nivel "macro" se integra en las relaciones laborales a partir de las configuraciones socio-económicas de cada periodo histórico que condicionan la forma de desarrollo de las relaciones en los otros niveles, pero además integra, a través del Estado, la diversidad de intereses que lo componen, es en este nivel donde se construyen las normas y reglas que regulan el mundo del trabajo.
} 
vinculadas al individual is mo norteamericano y su acción en otros países en el marco de regímenes regulatorios diferentes (Gunnigle, Lavelle y McDonnell, 2007). De esta forma se argumenta que el sistema de relaciones norteamericano es diferente al de otros países industrializados, pudiéndose hablar del "excepcionalismo americano" (Jacoby, 1985). Sería la nula o baja sindicalización la característica de ese excepcionalismo que busca imponerse en las filiales de esas mismas firmas, bajo las órdenes de los directivos de las empresas.

La búsqueda de evadir la presencia sindical, no solamente en las empresas norteamericanas, ha dado lugar al desarrollo de una serie de análisis que han puesto de manifiesto el efecto de la incorporación de ciertas formas de GFT como estrategias antisindicales. Estas prácticas que buscan dominar el escenario en la empresa son principalmente aquellas asociadas con la comunicación hacia los empleados, mecanismos de resolución de conflictos sin intervención sindical, participación de los trabajadores, mecanismos de selección de personal, capacitación para la implicación, evaluación de desempeño y pagos por rendimiento, entre otros (Lewchuk y Wells, 2006; Bartram y Cregan, 2003; Lavelle, Gunnigle y McDonnell, 2010; Dundon, Curran, Ryan y Maloney, 2006; Cooper et al, 2009).

Un aspecto clave del debate sobre el individualismo y relaciones laborales colectivas es el impacto sobre los sindicatos que tienen la incorporación de ciertas prácticas de gestión (Guest, 1987). En este sentido, la individualización de las relaciones laborales supone la fijación de las condiciones de trabajo y salariales sin la intermediación sindical $\mathrm{y}$ en todo caso negociada de manera directa entre el empleador y el trabajador. No obstante, existen situaciones intermedias que van desde la negociación descentralizada a nivel de empresa con intervención sindical hasta otras que se desenvuelven con grupos de trabajadores sin la participación de la representación sindical. Así, surge el interrogante de hasta qué punto pueden coexistir políticas de recursos humanos individualistas junto con las relaciones laborales "tradicionales" y reemplazar o reducir drásticamente el papel de los sindicatos y la negociación colectiva. En este sentido, se abren dos perspectivas. La primera se basa en la premisa de que la gestión vinculada al individual is mo contrarresta el carácter colectivo vinculado al sindicato (Foulkes, 1980; 1981; Purcell, 1987). Por lo tanto, cabe esperar que las empresas con estas formas de gestión procurarán evitar a los sindicatos y la negociación colectiva. Por su parte, la segunda de las perspectivas, denominada "dualismo" (Purcell, 1987; Brewster, 1993), sugiere que el individualismo no necesariamente contrarresta las lógicas y prácticas sindicales. Así es que las firmas pueden utilizar simultáneamente estrategias de individualización y de negociación con los sindicatos.

En este marco, aparecen algunas formas de SPV vinculadas a las prácticas de individualización, lo cual implica la extensión de recursos utilizados solamente para directores y mandos medios hacia los niveles operativos de las empresas, habitualmente sindicables. Algunas de las prácticas vinculadas a estos sistemas han sido vistas como formas de individualización que buscan fragmentar los colectivos laborales vinculados a los sindicatos, en la medida que imponen una diferenciación salarial entre los mismos trabajadores. Por su parte, los sindicatos han tratado de garantizar que las decisiones relativas a los salarios queden sujeta a la negociación colectiva. Sin embargo, algunos SPV, en particular los basados en la evaluación de desempeño, reflejan una orientación esencialmente individualista que excluye o limita la participación sindical (Gunnigle, 1995).

\section{Los sistemas de pagos variables en las empresas}


Los sistemas de pagos variables (SPV) en las empresas han cobrado un mayor impulso desde la década del 90, vinculados a los procesos de descentralización de las relaciones laborales y la negociación colectiva. $\mathrm{Su}$ rasgo definitorio es su intento explícito por hacer que una mayor proporción de la remuneración esté sujeta a criterios relacionados con el desempeño y los resultados, ya sea centrado en la empresa, el grupo de trabajo o el individuo (Marginso n, Arrowsmith y Gray, 2008). Es así que generalmente se distinguen tres formas de SPV. Primero, programas de remuneración individual relacionada con el desempeño que recompensan a los empleados en base a la evaluación de su desempeño laboral por parte de un superior. Estos suelen ser los más comunes y también los de mayor importancia cuantitativa, a la vez que conforman el mayor nivel de individualización salarial. Segundo, los incentivos que establecen un vínculo entre la remuneración y la producción de los trabajadores, como por ejemplo trabajos a destajo, pagos por resultados, comisiones y bonificaciones. Por último, esquemas a nivel de la organización, tales como planes de participación en beneficios y participación en acciones, que recompensen a los empleados sobre la base del desempeño de la empresa. Suelen ser anuales, y de menor importancia cuantitativa. Estos dos últimos tipos pueden estar negociados con los sindicatos $y$ avalados por estos, en la medida que el pago se desprende de elementos objetivos (Van het Kaar y Grünell, 2001).

Los primeros análisis acerca de los SPV identificaron la existencia de dos propósitos principales en su implementación. En primer lugar, una función de gestión, que se vincula a un aumento del control gerencial sobre los empleados para reducir los costos laborales mejorando la productividad. En segundo lugar, una función de mercado, referida a la necesidad de los gerentes de atraer, retener y motivar a aquellos empleados considerados adecuadamente calificados (Flanders, 1970). Estudios más recientes señalan que dicha distinción posee un valor analítico limitado puesto que en ocasiones ambos se entrecruzan, siendo a veces complementarias y otras conflictivas (Trif y Gaery, 2016).

Otros estudios han puesto el foco en establecer los patrones de toma de decisión de los gerentes acerca de los SPV, en relación a dos presiones coexistentes. Por un lado, la lógica de alineación estratégica a las casas matrices que puja por la creación de sistemas globales homogéneos, mientras que por otro lado existe la lógica cultural local, que exige la implementación de adaptaciones a los marcos normativos y culturales de las naciones donde se instalan las filiales (Bloom, Milkovich y Mitra, 2003). A su vez, en análisis en torno al origen del capital, se ha encontrado evidencia acerca de las particularidades de las empresas norteamericanas, que se caracterizan por la implementación de más tipos y mayores niveles de SPV, en comparación a países de Europa y Japón (Ferner y Almond, 2013).

Por su parte, Edwards (1998) ha identificado que las alternativas de transferencias o difusión de prácticas en EMN pueden ser tres: "Hacia adelante", cuando la transferencia es desde la casa matriz a sus filiales; "Horizontal", cuando se desarrolla la trasferencia entre las filiales; y "Difusión invertida" cuando éstas van desde las filiales a la matriz. Estos halla zgos han aportado una mayor complejidad a los anális is acerca de las prácticas de difus ión llevadas a cabo por las EMN.

También se ha abordado el estudio de los SPV a través de las diferencias existentes en su aplicación a diferentes grupos de empleados. Dølvik y Nergaard (2011) concluyeron que en Noruega los empleados de "cuello blanco" dedicados a los servicios bancarios cuentan con mayores diferenciaciones salariales debido a la implementación de pagos por desempeño individual, mientras que los empleados de "cuello azul" de empresas de 
producción de maquinaria tienen una mayor proporción de su salario atado a la negociación colectiva y por lo tanto sus diferenciaciones salariales se encuentran más restringidas. Por su parte, Ferner y Almond (2013) observaron las diferencias entre grupos de empleados de una misma empresa, distinguiendo entre los directivos y el área de mayor número de empleados. Siguiendo a Lepak y Snell (1999), las diferencias entre las distintas arquitecturas de RRHH para cada grupo de empleados se deben a sus respectivas singularidades $\mathrm{y}$ contribuciones a la ventaja competitiva. Es decir, las estrategias son diferentes según los empleados sean considerados únicos o cruciales, o no.

Por estas cuestiones, habitualmente se considera que los SPV están en contradicción con la lógica colectiva e igualitaria de las relaciones laborales y la negociación colectiva. Estos sistemas se encuentran en el centro de las estrategias de Recursos Humanos para decidir discrecionalmente las políticas de remuneración mediante la descentralización, individualización y diferenciación de los pagos, lo cual se contrapone a las formas colectivas de fijación salarial que intentan desarrollar los sindicatos (Dølvik y Nergaard, 2011). Así, los SPV pueden amenazar la seguridad de los ingresos de los trabajadores, generar una desigualdad entre las remuneraciones percibidas, al mismo tiempo que pueden socavar a los sindicatos, principalmente a través de la erosión de la identidad colectiva de los trabajadores y el compromiso con los sindicatos al tener efectos de motivación individual que debilitan a los representantes en el lugar de trabajo (Nergaard, Dølvik, Marginson, Arasanz Díaz y Bechter, 2009).

Las empresas multinacionales en la economía Argentina.

\footnotetext{
6 Información consultada en http://www.indec.gob.ar/, con fecha 03 de Junio de 2017.
}

Las EMN tienen un poder económico que las convierte en actores predominantes del proceso de globalización, capaces de influir sobre los frágiles sistemas políticos, económicos, sociales y territoriales de los países en desarrollo (Silveira, 2009). El poder económico de estas empresas se manifies ta, en parte, en el comportamiento de la inversión extranjera directa (IED). De acuerdo con la United Nations Conference on Trade and Development (UNCTAD), en 2007 la IED alcanzó un máximo de 1,97 billones de dólares y hacia el año 2016 la IED a nivel mundial, llegó a 1,746 billo nes de dólares (UNCTAD, 2017). A su vez, según la misma fuente, en 2007, las 79 mil EMN que controlaban 790 mil filiales alrededor del mundo, generaban un valor agregado que representaba el $11 \%$ del PIB mundial.

Argentina tuvo una fuerte presencia de empresas extranjeras a lo largo de su historia, las que han mostrado tener una importancia central en la economía doméstica. De esta manera y en el marco de la trayectoria seguida por la IED, la economía argentina se encuentra altamente transnacionalizada. Según datos de la Encuesta Nacional a Grandes Empresas (ENGE) del Instituto Nacional de Estadísticas y Censo (INDEC) el número de empresas con participación de capitales extranjeros entre las 500 firmas más grandes del país se incrementó de 219 en 1993 a 316 en 2014, aunque alcanzó el pico de 340 en el año 2002. Asimismo, la participación de las empresas con capital extranjero en el valor agregado de ese conjunto de empresas pasó de $62 \%$ en 1993 al $77,4 \%$ en $2014^{6}$, con una absorción del $62,2 \%$ del trabajo asalariado.

En términos de la presencia de EMN, las filiales que operan en la Argentina en los sectores de Industria, comercio y servicios son 1140 y su participación en el empleo representaba 
$12 \%$ del total del empleo registrado. En cuanto a su distribución sectorial, $37 \%$ son empresas industriales; $20 \%$ están dedicadas a las actividades de comercio y $44 \%$ participan del sector servicios. En lo que se refiere al origen de capital, el $42 \%$ son filiales de empresas que tienen su casa matriz en EE.UU. y una proporción algo menor $(40 \%)$ se concentra entre los países europeos, de Alemania, Italia, Francia y España; el resto de los países europeos representan $8 \%$ del total, mientras que Brasil y Chile tienen una participación del $5 \%$ en el conjunto de EMN. Por otro lado, las EMN de origen argentina representan el $2 \%$ y el resto de los países explican el $3 \%$ (fuente: MTEySS).

\section{La fijación salarial en el marco de las relaciones laborales en Argentina}

En Argentina, el sistema de relaciones laborales comienza a tomar forma en la década del 40 con el advenimiento del peronismo, al menos en sus aspectos formales, que le ha dado una impronta fundacional que, a pesar de los cambios generales por los cuales ha atravesado, continúa tiñendo la cultura laboral en la Argentina (Delfini 2011). Este modelo se caracterizó por: 1) una fuerte intervención estatal, protectoria, a través de su rol político de homologador de los acuerdos y Convenios Colectivos de Trabajo (CCT) y de su activa participación en la conformación de los actores del movimiento sindical y su perfil (otorgando o no personería gremial); 2) a partir de esto, el fortalecimiento del poder institucional verticalizado del sindicato y del modelo de sindicato único cuya base estructural se asienta en las comisiones internas y el cuerpo de delegados; 3) la extensión de la negociación colectiva centralizada por rama de actividad junto con la evolución de las remuneraciones en base a la indexación y mediante la negociación colectiva, complementado por un amplio sistema de previsión y seguridad social (garantizado tanto por el Estado como por el sindicato).
La participación de los trabajadores se canaliza por medio de los delegados o comisiones internas, quienes son los representantes de los asalariados en la empresa y de los sindicatos en la firma, dando como resultado una representación única en la empresa. Asimismo, la posibilidad de tener delegados en las empresas se da en aquellas que tengan más de 10 empleados y la afiliación solo es posible entre los asalariados formales, es decir los que se encuentran registrados por sus empleadores y tiene un carácter voluntario. La conformación por parte de los sindicatos de obras sociales y la presencia sindical en los espacios de trabajo de los representantes fue consolidando altos niveles de afiliación, en la medida que estos dos elementos posibilitaron un vínculo más estrecho entre los trabajadores y las organizaciones sindicales.

Durante la década del ' 90 se asiste en Argentina a un proceso de profundización de las demandas empresarias por una mayor desregulación y flexibilización de las condiciones de trabajo. Durante esta década se pusieron en marcha mecanismos desregulatorios y se implementó un nuevo herramental jurídico en materia laboral elaborado a la luz de la ideología neoliberal.

A pesar de los cambios experimentados, para 2005 y luego de la oleada neoliberal, la tasa de afiliación entre los trabajadores formales de empresas privadas, alcanzaba un nivel elevado de $41 \%$, siendo uno de los determinantes fundamentales para sostener esos elevados niveles de afiliación, la presencia de representantes sindicales en el espacio de trabajo. Al respecto, se observó que allí donde había delegados, la afiliación llegaba a $49 \%$, mientras donde no había presencia sindical la afiliación alcanzaba $36 \%$ (Delfini, 2011).

La negociación colectiva en Argentina comprende tanto la firma de Convenios Colectivos de Trabajo (CCT) como acuerdos. Los primeros conforman un cuerpo de normas que regulan las 
condiciones de trabajo en las empresas que deben ser homologados por el Estado, y si bien tienen una fecha de duración estipulada, también tienen la capacidad de mantenerse vigentes mientras no se negocie uno nuevo. Esto, denominado "ultra actividad", protege a los trabajadores de cualquier demora que pueda surgir en los procesos de negociación. Los CCT pueden ser firmados a nivel de actividad entre las cámaras empresarias reconocidas en la actividad $y$ el sindicato de esa misma actividad o bien a nivel de empresa y con el sindicato de la actividad correspondiente (en la medida en que en Argentina no existen sindicatos de empresa). Por su parte, los acuerdos se refieren básicamente a la firma y homologación de negociaciones sobre cuestiones específicas y que tienen un límite de tiempo. A diferencia de los CCT, estos concluyen en el momento estipulado en su firma. Una gran parte de los acuerdos refieren a modificaciones salariales.

Bajo este marco la negociación colectiva, históricamente desarrollada a nivel de la actividad económica, aumentó cuantitativamente en el nivel de empresa durante los '90 (esto estructuró una negociación colectiva que se mantiene en la actualidad). Esta descentralización de la negociación fue la llave que permitió el ingreso de un nuevo articulado convencional que chocaba de frente con la estructuración histórica de la negociación colectiva en la Argentina. Así, aparecen novedosas cláusulas que tienden a flexibilizar las formas de disponibilidad del trabajo al capital: multiplicación de formas de contratación, reestructuración de la jornada de trabajo, desdibujamiento de las categorías profesionales de manos de la polivalencia, la variabilidad salarial, la imposición de formas de evaluación del personal con impacto en las trayectorias laborales, imposición de cláusulas limitativas del conflicto laboral, etc.

7 Debe considerarse que existe un nivel de centralización mayor donde el salario es fijado entre empresarios, gobierno y confederaciones sindicales
Vinculado al desenvolvimiento de las relaciones laborales y la negociación colectiva en Argentina se desarrolla la fijación de los salarios. Así como la negociación colectiva supuso hasta la década del '90 una fuerte centralización, lo mismo ocurrió con la fijación salarial. La descentralización de la negociación colectiva operada desde los '90 implicó también un proceso de descentralización en la fijación de los salarios pasando a prevalecer la empresa como eje de su determinación. De esta manera, se plasmó una lógica salarial de diversos niveles. Una centralizada por actividad o rama, cuya fijación salarial corresponde a la negociación entre las cámaras empresarias del sector y el sindicato, y un nivel descentralizado donde el salario es negociado entre la empresa y el sindicato de actividad. En el primer caso, la fijación salarial responde a una lógica colectiva en la medida que interviene el sindicato y se fija el salario de manera homogénea para todos los trabajadores ${ }^{7}$.

El segundo de los casos se corresponde con un nivel más descentralizado donde los salarios son fijados entre el sindicato y la empresa. En este sentido, supone la existencia de la presencia sindical. También podemos ubicar en este nivel a aquellas firmas que toman la negociación salarial del sector, pero la fijación del salario corresponde a la determinación de la empresa. Aquí pueden integrarse aquellas que toman el promedio salarial de la actividad y lo fijan para sus empleados.

Un mayor nivel de descentralización corresponde a la posibilidad de incorporar partes variables a los salarios. Aquí también podemos encontrar diversos niveles, el primero contempla al conjunto de empleados de la empresa, el segundo implica el pago de una parte variable del salario a nivel de equipo o grupo de trabajo de una empresa y el último corresponde con

y corresponde al salario mínimo vital y móvil, que indica que ningún salario puede estar por debajo de este. 
la individualización salarial, es decir cada uno de los trabajadores cobran salarios diferentes. En los dos primeros casos, puede tratarse de distribución de ganancias, pagos por rendimiento, ya sea mejoras en la productividad como cumplimiento de objetivos. El caso de la individualización salarial, puede estar atada al rendimiento o a las evaluaciones de desempeño. Estos mecanismos de pagos variables pueden ser negociados con los sindicatos o bien impuestos por las empresas, aunque se considera por una parte que allí donde hay representación sindical, ello puede ser negociado, en tanto que por la otra se sostiene que las lógicas de individualización salarial buscan heterogeneizar los rasgos colectivos de trabajo y debilitar a los sindicatos.

\section{Datos y metodología}

El análisis que presentamos tiene como punto de partida la investigación sobre EMN desarrollada en la UNGS y financiada por el MINCyT, que contempla diversas etapas para su realización. Al respecto, esta primera etapa, cuyo algunos de los resultados presentamos aquí, tiene un carácter exploratorio, que será complementado en la segunda etapa con otras herramientas y técnicas metodológicas. Bajo este marco y con el fin de dar cuenta de las diversas formas que adquieren las relaciones laborales y la gestión de la fuerza del trabajo en las EMN se llevaron adelante doce entrevistas semiestructuradas a gerentes y empleados del área de recursos humanos de las filiales locales de empresas extranjeras. Para la selección de los casos se tuvieron en cuenta dos criterios. En primer lugar, que las firmas tuviesen más de 100 empleados, y que tuviesen su casa matriz en Estados Unidos o Europa. Estas entrevistas fueron concretadas telefónicamente de manera aleatoria, a partir de una base de datos armada con información proveniente de diferentes cámaras de comercio bilaterales, y realizadas en la oficina de cada una de las empresas, cuya duración aproximada fue de 1 hora.

Como muestra el Cuadro 1, las empresas han sido divididas entre las de origen de Estados Unidos (E) y Europeas (O). En lo que se refiere a las firmas de E, tres pertenecen al sector servicio (ES) y tres al industrial (EI), mientras que las denominadas $\mathrm{O}$, corresponden dos a servicios (OS) y cuatro a la actividad industrial (OI). Dentro de estas firmas nos encontramos con aquellas que ingresaron al mercado local a través de la compra de otras firmas, las que lo hicieron antes de la década del 80 (Vieja instalación) y las que comenzaron sus actividades en los 90 (Nueva creación). En torno a los procesos de negociación colectiva, las firmas han mantenido predominantemente una negociación por actividad, firmándose en algunas de ellas acuerdos a nivel de empresa. En tanto que una de las firmas, que tiene actividades en diferentes sectores, en uno de los que interviene ha descentralizado la negociación a nivel empresa. Por su parte, entre el conjunto de estas firmas, se observa que en las filiales de origen estadouniden ses predomina una estrategia de recursos humanos que hemos nominado como integrada de control, lo que refiere a que el área de recursos humanos se encuentra integrada a un nivel superior (Casa Matriz o Filial que concentra las decisiones regionales) y existe una baja autonomía para definir cuestiones relacionadas con el área. Entre las firmas europeas del sector industrial (OI) predomina una estrategia local, la cual refiere a que no existe integración a un nivel superior y hay un nivel elevado de autonomía para definir las cuestiones vinculadas a la gestión de la fuerza de trabajo. En tanto que las empresas con una estrategia de control parcial son aquellas que presentan una de las dos características, o bien cuentan con autonomía o no se encuentran integradas a un nivel superior. 
(En)Cena

Cuadro 1: Características de las empresas ${ }^{8}$.

\begin{tabular}{|c|c|c|c|c|c|c|c|}
\hline $\begin{array}{c}\text { Origen } \\
\text { del } \\
\text { capital }\end{array}$ & Empresa & Actividad & $\begin{array}{c}\text { Empleo } \\
\text { en } \\
\text { Argentina }\end{array}$ & $\begin{array}{c}\text { Empleo } \\
\text { Mundial }\end{array}$ & $\begin{array}{c}\text { Año de } \\
\text { ingreso al } \\
\text { mercado } \\
\text { Local }\end{array}$ & CCT & $\begin{array}{c}\text { Estrategia } \\
\text { de RR } \\
\text { HH }\end{array}$ \\
\hline Europa & OI1 & Industria & 4.000 & 100.000 & $\begin{array}{c}\text { Compra } \\
\text { Década del } \\
90\end{array}$ & Por Actividad & Local \\
\hline Europa & OI2 & Industria & 320 & 30.000 & $\begin{array}{l}\text { Nueva } \\
\text { creación }\end{array}$ & Por Actividad & Local \\
\hline Europa & $\mathrm{OI} 3$ & Industria & 1.569 & 4.100 & $\begin{array}{c}\text { Vieja } \\
\text { Instalación }\end{array}$ & Por empresa & Local \\
\hline Europa & OI4 & Industria & 2.500 & 280.000 & $\begin{array}{c}\text { Vieja } \\
\text { Instalación }\end{array}$ & $\begin{array}{l}\text { Por Actividad y } \\
\text { por empresa } \\
\text { dependiendo del } \\
\text { sector }\end{array}$ & $\begin{array}{l}\text { Integrada } \\
\text { de control }\end{array}$ \\
\hline Europa & OS5 & Servicios & 420 & 11.700 & $\begin{array}{l}\text { Nueva } \\
\text { Creación }\end{array}$ & Actividad & $\begin{array}{l}\text { Integrada } \\
\text { de control }\end{array}$ \\
\hline Europa & OS6 & Servicios & 290 & 6.000 & $\begin{array}{l}\text { Nueva } \\
\text { creación }\end{array}$ & Actividad & $\begin{array}{l}\text { Control } \\
\text { Parcial }\end{array}$ \\
\hline $\begin{array}{c}\text { Estados } \\
\text { Unidos }\end{array}$ & EI1 & Industria & 332 & 27.000 & $\begin{array}{c}\text { Compra- } \\
\text { Década del } \\
90\end{array}$ & $\begin{array}{c}\text { Por } \\
\text { Actividad/Firma } \\
\text { acuerdos por } \\
\text { empresa }\end{array}$ & Local \\
\hline $\begin{array}{c}\text { Estados } \\
\text { Unidos }\end{array}$ & $\mathrm{EI} 2$ & Industria & 1.500 & 50.000 & $\begin{array}{c}\text { Vieja } \\
\text { Instalación }\end{array}$ & Actividad & $\begin{array}{l}\text { Control } \\
\text { Parcial }\end{array}$ \\
\hline $\begin{array}{c}\text { Estados } \\
\text { Unidos }\end{array}$ & $\mathrm{EI} 3$ & Industria & 320 & 47.000 & $\begin{array}{c}\text { Vieja } \\
\text { Instalación }\end{array}$ & $\begin{array}{c}\text { Por } \\
\text { Actividad/Firma } \\
\text { acuerdos por } \\
\text { empresa }\end{array}$ & $\begin{array}{l}\text { Integrada } \\
\text { de control }\end{array}$ \\
\hline $\begin{array}{c}\text { Estados } \\
\text { Unidos }\end{array}$ & ES4 & Servicios & 7.000 & 384.000 & $\begin{array}{l}\text { Nueva } \\
\text { creación }\end{array}$ & Actividad & $\begin{array}{l}\text { Integrada } \\
\text { de control }\end{array}$ \\
\hline $\begin{array}{c}\text { Estados } \\
\text { Unidos }\end{array}$ & ES5 & Servicios & 120 & 24.000 & $\begin{array}{c}\text { Compra } \\
\text { Década del } \\
90\end{array}$ & Actividad & $\begin{array}{l}\text { Integrada } \\
\text { de control }\end{array}$ \\
\hline $\begin{array}{c}\text { Estados } \\
\text { Unidos }\end{array}$ & ES6 & Servicios & 2.400 & 180.000 & $\begin{array}{c}\text { Compra } \\
\text { Década del } \\
90\end{array}$ & Actividad & $\begin{array}{l}\text { Control } \\
\text { Parcial }\end{array}$ \\
\hline
\end{tabular}

Fuente: Elaboración propia sobre entrevistas realizadas a EMN.

Asimismo, se puede establecer que se trata de grandes empresas a nivel mundial y también en Argentina, país cuyo promedio de empleo llega a 1.730 ocupados. Entre las firmas de E, el promedio llega a 1945 empleados y entre las O alcanza 1516. Como se observa en este cuadro, a su vez las empresas de Europa tienen un mayor número promedio de empleados entre las firmas industriales, mientras que las de Estados Unidos concentran la ocupación en el sector servicios.

\section{Un análisis sobre los pagos variables en EMN de Argentina}

\footnotetext{
${ }^{8}$ Las características de las empresas fueron desarrolladas a partir de las entrevistas realizadas a los gerentes de recursos humanos, a excepción de OS6 y EI1, donde los entrevistados fueron empleados con más de dos años en la empresa.
} 
Para avanzar en nuestro análisis, hemos sintetizado los SPV y la penetración sindical sobre dos ejes cada uno de ellos (Cuadro 2). En el primer caso, se observó la existencia de sistemas de evaluación de desempeño (ED) y el desarrollo de pagos variables en el salario, en tanto que, en el segundo, se tuvo en consideración si había presencia sindical y el nivel de afiliación. Para el caso de la ED, se tuvo en cuenta el alcance (categorías de empleados alcanzados), básicamente estableciendo si llegaba a los empleados que se encontraban bajo CCT, el tipo de evaluación, como así también las consecuencias de las mismas. En torno a los pagos variables que podían conformar el salario, se tuvo en cuenta si existía y el carácter del mismo. En cuanto a la presencia sindical se observó si en las empresas había delegados sindicales y también el nivel de afiliación.

Cuadro 2: Empresas según evaluación de desempeño, pagos variables y penetración sindical

\begin{tabular}{|c|c|c|c|c|c|c|}
\hline Empresa & $\begin{array}{l}\text { Evaluación de } \\
\text { desempeño }\end{array}$ & $\begin{array}{l}\text { Consecuencias } \\
\text { de la } \\
\text { Evaluación }\end{array}$ & $\begin{array}{l}\text { Tipo de } \\
\text { evaluación }\end{array}$ & $\begin{array}{l}\text { Pagos } \\
\text { Variables }\end{array}$ & $\begin{array}{l}\text { Delegados } \\
\text { sindicales }\end{array}$ & $\begin{array}{l}\text { Nivel de } \\
\text { afiliación }\end{array}$ \\
\hline OI1 & $\begin{array}{l}\text { Propuesta por la } \\
\text { matriz } \\
\text { Alcanza sólo a } \\
\text { los mandos } \\
\text { medios } \\
\text { gerentes. Con } \\
\text { posible } \\
\text { implementación } \\
\text { para operarios. } \\
\text { En proceso de } \\
\text { negociación }\end{array}$ & $\begin{array}{l}\text { Para los } \\
\text { mandos medios } \\
\text { repercute en el } \\
\text { bono anual que } \\
\text { paga la } \\
\text { empresa }\end{array}$ & $\begin{array}{l}\text { Se evalúan los } \\
\text { objetivos y las } \\
\text { competencias. } \\
\text { La realiza el } \\
\text { superior } \\
\text { inmediato. Se } \\
\text { organiza desde } \\
\text { la matriz, pero } \\
\text { una parte es } \\
\text { armada en la } \\
\text { filial }\end{array}$ & $\begin{array}{l}\text { Sólo para } \\
\text { empleados } \\
\text { que están } \\
\text { fuera de CCT- } \\
\text { Los que están } \\
\text { dentro del } \\
\text { CCT tienen un } \\
\text { pago por } \\
\text { presentismo }\end{array}$ & Sí & $\begin{array}{l}90 \% \text { de los } \\
\text { que se } \\
\text { encuentran } \\
\text { bajo CCT y } \\
65 \% \text { del } \\
\text { total de la } \\
\text { empresa }\end{array}$ \\
\hline OI2 & $\begin{array}{l}\text { Propuesta por la } \\
\text { matriz } \\
\text { Alcanza sólo a } \\
\text { los mandos } \\
\text { medios } \\
\text { gerentes }\end{array}$ & $\begin{array}{l}\text { Para los } \\
\text { mandos medios } \\
\text { repercute en el } \\
\text { bono anual y } \\
\text { capacitación }\end{array}$ & $\begin{array}{l}\text { Se evalúan } \\
\text { objetivos y } \\
\text { competencias. } \\
\text { La realiza el } \\
\text { superior } \\
\text { inmediato. Se } \\
\text { organiza desde } \\
\text { la matriz, pero } \\
\text { el momento de } \\
\text { la } \\
\text { administración } \\
\text { y como se } \\
\text { administra } \\
\text { depende de la } \\
\text { la filial }\end{array}$ & $\begin{array}{l}\text { Los que están } \\
\text { dentro del } \\
\text { CCT tienen un } \\
\text { pago por } \\
\text { presentismo. } \\
\text { Se está } \\
\text { buscando } \\
\text { incorporar un } \\
\text { premio por } \\
\text { productividad. }\end{array}$ & Sí & $\begin{array}{l}80 \% \text { de los } \\
\text { que se } \\
\text { encuentran } \\
\text { bajo CCT y } \\
60 \% \text { del } \\
\text { total de la } \\
\text { empresa }\end{array}$ \\
\hline $\mathrm{OI} 3$ & $\begin{array}{l}\text { Propuesta por la } \\
\text { Filial Argentina } \\
\text { a ser } \\
\text { implementada a } \\
\text { nivel Global - } \\
\text { Alcanza a todos } \\
\text { los empleados } \\
\text { de forma } \\
\text { diferencial }\end{array}$ & $\begin{array}{l}\text { Se abona un } \\
\text { plus a todos los } \\
\text { empleados con } \\
\text { evaluaciones } \\
\text { positivas }\end{array}$ & $\begin{array}{l}\text { Se evalúan } \\
\text { objetivos y } \\
\text { competencias } \\
\text { para mandos } \\
\text { medios y } \\
\text { superiores y } \\
\text { sólo } \\
\text { competencias } \\
\text { para la parte } \\
\text { operativa. La } \\
\text { realiza el } \\
\text { superior } \\
\text { inmediato. }\end{array}$ & $\begin{array}{l}\text { Se le otorgan a } \\
\text { todos los } \\
\text { empleados en } \\
\text { forma de bono } \\
\text { anual } \\
\text { relacionado } \\
\text { con los } \\
\text { beneficios de } \\
\text { la empresa }\end{array}$ & Sí & $\begin{array}{l}65 \% \text { de los } \\
\text { que se } \\
\text { encuentran } \\
\text { bajo CCT y } \\
40 \% \text { del } \\
\text { total de la } \\
\text { empresa }\end{array}$ \\
\hline
\end{tabular}




\begin{tabular}{|c|c|c|c|c|c|c|}
\hline OI4 & $\begin{array}{l}\text { Propuesta por la } \\
\text { matriz - } \\
\text { Alcanza a todos } \\
\text { los empleados. }\end{array}$ & $\begin{array}{l}\text { La calificación } \\
\text { de la } \\
\text { evaluación } \\
\text { influye en el } \\
\text { incremento } \\
\text { anual de salario } \\
\text { en los mandos } \\
\text { medios y en los } \\
\text { cambios de } \\
\text { categorías en } \\
\text { los sectores } \\
\text { operativos }\end{array}$ & $\begin{array}{l}\text { Se evalúan } \\
\text { objetivos y } \\
\text { competencias. } \\
\text { Se pasó de } \\
\text { realizar dos a } \\
\text { una por año. } \\
\text { Hay } \\
\text { proceso de de } \\
\text { feedback, de } \\
\text { manera } \\
\text { periódica para } \\
\text { verobjetivos }\end{array}$ & $\begin{array}{l}\text { Solamente a } \\
\text { los niveles } \\
\text { medios y } \\
\text { gerenciales }\end{array}$ & Sí & $\begin{array}{l}70 \% \text { de los } \\
\text { que se } \\
\text { encuentran } \\
\text { bajo CCT y } \\
40 \% \text { del } \\
\text { total de la } \\
\text { empresa }\end{array}$ \\
\hline OS5 & $\begin{array}{l}\text { Propuesta por la } \\
\text { matriz } \\
\text { Alcanza a todos } \\
\text { los empleados }\end{array}$ & 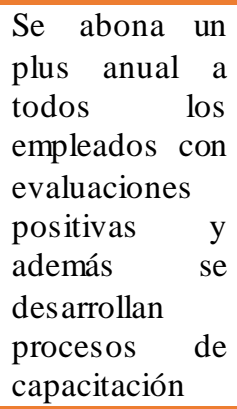 & $\begin{array}{l}\text { Se evalúan } \\
\text { objetivos y } \\
\text { competencias. } \\
\text { La realiza el } \\
\text { superior } \\
\text { inmediato por } \\
\text { medio del } \\
\text { método } 360\end{array}$ & $\begin{array}{l}\text { Se otorga a los } \\
\text { empleados en } \\
\text { función de los } \\
\text { objetivos } \\
\text { alcanzados a } \\
\text { nivel de la } \\
\text { empresa e } \\
\text { individuales }\end{array}$ & No & - \\
\hline OS6 & $\begin{array}{l}\text { Propuesta por la } \\
\text { matriz } \\
\text { Alcanza a todos } \\
\text { los empleados }\end{array}$ & $\begin{array}{l}\text { Se abona un } \\
\text { plus anual a } \\
\text { todos los } \\
\text { empleados con } \\
\text { evaluaciones } \\
\text { positivas. Ese } \\
\text { plus se vincula } \\
\text { con un ranking } \\
\text { que se } \\
\text { establece por } \\
\text { medio de las } \\
\text { evaluaciones }\end{array}$ & $\begin{array}{l}\text { Se evalúan los } \\
\text { objetivos una } \\
\text { vez por año, } \\
\text { los cuales son } \\
\text { revisados junto } \\
\text { al superior } \\
\text { inmediato en la } \\
\text { mitad del } \\
\text { proceso }\end{array}$ & $\begin{array}{l}\text { Se otorga a los } \\
\text { empleados en } \\
\text { función de los } \\
\text { objetivos } \\
\text { alcanzados a } \\
\text { nivel de la } \\
\text { empresa e } \\
\text { individuales }\end{array}$ & No & - \\
\hline EI1 & $\begin{array}{lr}\text { Propuesta } & \text { por } \\
\text { casa matriz } & \text { para } \\
\text { aplicarse } & \text { a } \\
\text { todos } & \text { los } \\
\text { empleados } & \end{array}$ & $\begin{array}{l}\text { En los niveles } \\
\text { medios y } \\
\text { superiores } \\
\text { influye en los } \\
\text { incentivos y los } \\
\text { incrementos de } \\
\text { salario }\end{array}$ & $\begin{array}{l}\text { Se evalúan } \\
\text { objetivos y } \\
\text { competencias. } \\
\mathrm{La} \mathrm{realiza} \mathrm{el} \\
\text { superior } \\
\text { inmediato }\end{array}$ & $\begin{array}{l}\text { Sólo para } \\
\text { empleados } \\
\text { que están } \\
\text { fuera de CCT }\end{array}$ & Sí & $\begin{array}{l}80 \% \text { de los } \\
\text { que se } \\
\text { encuentran } \\
\text { bajo CCT y } \\
43 \% \text { del } \\
\text { total de la } \\
\text { empresa }\end{array}$ \\
\hline EI2 & $\begin{array}{l}\text { Propuesta por la } \\
\text { matriz } \\
\text { Alcanza } \\
\text { algunos } \\
\text { empleados }\end{array}$ & $\begin{array}{l}\text { Alcanza a los } \\
\text { niveles medios } \\
\text { y superiores. } \\
\text { Para estos, se } \\
\text { otorga un bono } \\
\text { anual en } \\
\text { función de los } \\
\text { objetivos } \\
\text { alcanzados. A } \\
\text { los operarios } \\
\text { sólo donde lo } \\
\text { permite el } \\
\text { CCT, ya que la } \\
\text { empresa tiene } \\
\text { diferentes } \\
\text { actividades. }\end{array}$ & $\begin{array}{lr}\text { Se evalúan los } \\
\text { objetivos. } & \text { La } \\
\text { realiza } & \text { el } \\
\text { superior } & \\
\text { inmediato } & \end{array}$ & $\begin{array}{l}\text { Los que se } \\
\text { encuentran } \\
\text { bajo CCT } \\
\text { reciben por } \\
\text { presentismo y } \\
\text { puntualidad }\end{array}$ & Sí & $\begin{array}{l}60 \% \text { de los } \\
\text { que se } \\
\text { encuentran } \\
\text { bajo CCT y } \\
40 \% \text { del } \\
\text { total de la } \\
\text { empresa }\end{array}$ \\
\hline $\mathrm{EI} 3$ & $\begin{array}{l}\text { Propuesta por la } \\
\text { matriz }\end{array}$ & $\begin{array}{l}\text { Se abona un } \\
\text { plus a todos los }\end{array}$ & $\begin{array}{l}\text { Se evalúan los } \\
\text { objetivos. La }\end{array}$ & $\begin{array}{l}\text { Hay variables } \\
\text { por objetivo y }\end{array}$ & Sí & $\begin{array}{l}60 \% \text { de los } \\
\text { empleados }\end{array}$ \\
\hline
\end{tabular}




\begin{tabular}{|c|c|c|c|c|c|c|}
\hline & $\begin{array}{l}\text { Alcanza a todos } \\
\text { los empleados }\end{array}$ & $\begin{array}{l}\text { empleados con } \\
\text { evaluaciones } \\
\text { positivas y } \\
\text { puede derivar } \\
\text { en procesos de } \\
\text { capacitación }\end{array}$ & $\begin{array}{ll}\text { realiza } & \text { el } \\
\text { superior } & \\
\text { inmediato } & \end{array}$ & $\begin{array}{l}\text { productividad } \\
\text { general }\end{array}$ & & $\begin{array}{l}\text { se } \\
\text { encuentran } \\
\text { bajo CCT y } \\
10 \% \text { de } \\
\text { ellos están } \\
\text { afiliados }\end{array}$ \\
\hline ES4 & $\begin{array}{l}\text { Armada, } \\
\text { organizada y } \\
\text { aplicada a nivel } \\
\text { global } \\
\text { Alcanza a todos } \\
\text { los empleados }\end{array}$ & $\begin{array}{l}\text { Se abona un } \\
\text { plus a todos los } \\
\text { empleados con } \\
\text { evaluaciones } \\
\text { positivas y } \\
\text { puede derivar } \\
\text { en mejoras } \\
\text { salariales }\end{array}$ & $\begin{array}{l}\text { Se evalúan las } \\
\text { fortalezas, } \\
\text { performance } \\
\text { general, } \\
\text { cumplimiento } \\
\text { de objetivos y } \\
\text { capacidades. } \\
\text { Se realiza una } \\
\text { autoevaluación } \\
\text { y luego con el } \\
\text { superior } \\
\text { inmediato }\end{array}$ & $\begin{array}{l}\text { Se realizan } \\
\text { por objetivos }\end{array}$ & No & - \\
\hline ES5 & $\begin{array}{l}\text { Propuesta por la } \\
\text { matriz } \\
\text { Alcanza a todos } \\
\text { los empleados }\end{array}$ & $\begin{array}{l}\text { De acuerdo a la } \\
\text { calificación se } \\
\text { otorgan } \\
\text { aumentos en } \\
\text { los salarios }\end{array}$ & \begin{tabular}{l} 
Se evalúan los \\
objetivos que \\
cadauno de los \\
empleados se \\
propone al \\
comenzar el \\
año \\
\multicolumn{2}{c}{ competencias }
\end{tabular} & No se realizan & No & $\begin{array}{l}30 \% \text { se } \\
\text { encuentra } \\
\text { bajo CCT y } \\
\text { no hay } \\
\text { afiliados }\end{array}$ \\
\hline ES6 & $\begin{array}{l}\text { Propuesta por la } \\
\text { matriz } \\
\text { Alcanza a todos } \\
\text { los empleados }\end{array}$ & $\begin{array}{l}\text { De acuerdo a la } \\
\text { calificación se } \\
\text { otorgan } \\
\text { aumentos en } \\
\text { los salarios } \\
\text { sólo a los } \\
\text { mandos medios } \\
\text { o gerentes }\end{array}$ & $\begin{array}{l}\text { Se evalúa el } \\
\text { desempeño } \\
\text { general de } \\
\text { manera anual }\end{array}$ & $\begin{array}{l}\text { Se paga un } \\
\text { variable por } \\
\text { calidad }\end{array}$ & Sí & $\begin{array}{l}40 \% \text { se } \\
\text { encuentra } \\
\text { bajo CCT y } \\
20 \% \text { está } \\
\text { afiliado }\end{array}$ \\
\hline
\end{tabular}

Fuente: Elaboración propia sobre entrevis tas realizadas a EMN.

El primer elemento que puede establecerse es la extensión que tienen las prácticas de SPV ligadas a la evaluación de desempeño, ya que es desarrollada en todas las empresas. En este mismo sentido sobresale también la aplicación global de las evaluaciones estandarizadas, confeccionadas en el país de origen de la EMN, con excepción de dos empresas, marcando la alineación estratégica a las casas matrices (Bloom, et al; 2003). Lo que se modifica entre las firmas analizadas es el alcance de las mismas. Al respecto, entre las Empresas de E en 5 de los 6 casos se aplica una evaluación al conjunto del personal, incluyendo los trabajadores que están bajo $\mathrm{CCT}$, en tanto que entre las $\mathrm{O}$ se observa que su aplicación para todos los empleados es de 4 entre 6. Asimismo, un dato importante es que en todas las firmas de servicios se aplica para el conjunto de las categorías laborales. De esta forma, allí donde se desarrollan las ED y coexisten con la presencia de los sindicatos, se puede hablar de "dualismo", en la medida que las lógicas individualistas que supone la existencia de evaluaciones de desempeño no frena las prácticas sindicales. Asimis mo se puede resaltar que las evaluaciones de desempeño tienden a cumplir una "Función de gestión" ya que las mismas aparecen como un elemento de mayor control sobre los trabajadores.

Otro de los elementos a resaltar, se vincula con las estrategias de las EMN en torno a la formulación de su política vinculados a la gestión de la fuerza de trabajo. Se observa que las ED son 
desarrolladas y difundidas por la casa matriz hacia sus filiales en 10 de los casos analizados, en tanto que en los otros 2 se desarrollan distintas alternativas. Recordando los tipos de difusión de prácticas en EMN de Edwards, se observa el desarrollo de una estrategia de carácter "horizontal" (ES4) y otra del tipo de una "difusión invertida" (OI3):

"Se realiza para todas las categorías... De operarios hasta Gerentes... De hecho se desarrolló en Argentina... Es una herramienta que está en la nube, nueva tecnología que se utiliza, así que la instrumentamos por ese medio y lo implementamos primero sólo para Argentina, es una nueva experiencia... Y la están probando en otras filiales. La idea es que se lleve adelante en todas en un par de años. Se evalúan objetivos en casi todas las categorías... Se evaluan objetivos y competencias... Las competencias varían por jerarquías... Los operarios tienen una; los analistas, asistentes y coordinadores tienen otro set de competencias; los jefes otro y los gerentes otro... Asi que según los objetivos cumplidos más las competencias, el jefe lo que hace es ponderar y poner una calificación final a la persona. Ese es el proceso que involucra a objetivos, competencias y la solicitud del jefe de capacitación para esa persona y, además, hay un feedback que el jefe brinda por escrito... Asi la persona, más allá de la reunión personal, tenga la evaluación por escrito... Como resumen... Está asociado a una gratificación que, obviamente está atada a los resultados de la compañía, y al cumplimiento de objetivos individuales..." (OI3)

En los casos analizados se lleva adelante una evaluación anual, donde se toman en consideración las competencias alcanzadas y los objetivos propuestos en el año anterior. En este sentido, a partir de su cumplimiento se alcanza un incremento salarial o bien se obtiene el pago de un bono, para los casos que así se determinen. En esta dirección se puede incorporar el relato de los gerentes de las empresas ES5 y EI3:

"....el gerente hace la evaluación a mitad de año, tienen un feedback para ponerse de acuerdo cómo van a seguir durante la segunda mitady a fin de año funciona de la misma manera, esto queda cargado en el sistema y cuando nos asignan el presupuesto para incremento salarial la distribución depende de esa calificación de cumplimiento de objetivos, si yo tengo a cargo un área de 10 personas y tengo uno que tiene 10 de evaluación y otro que tiene un 4 y tengo un $20 \%$ para distribuir le voy a dar un 5 al que tiene 4 y un 15 al que tiene 10, así que afecta de manera directa los aumentos salariales. En el caso de los operarios es similar, lo supervisores hacen la evaluación con ellos, donde se evalúa cumplimiento de objetivos y también competencias" (ES5).

"Tenemos evaluación de desempeño en febrero... Desarrollada por la Casa Matriz y se lleva adelante en todas las áreas y en el caso de las personas que no les vabien, 
por algún motivo no sacaron una buena nota, se hace una a mitad de año con un plan de mejora, un plan de trabajo... Se trabaja en conjunto con esa persona para que se vuelva a evaluar y ver qué pasa en su desempeño. Para los que obtienen evaluaciones positivas se les otorga un bono anual" (EI3).

Un dato a destacar y que muestra la conexión entre la implementación de las ED y los sindicatos es que allí donde no hay representación sindical o los niveles de afiliación son bajos la ED alcanza a los mandos medios y en menor medida a los trabajadores que se encuentran bajo CCT, y en algunos casos donde se desarrolla ED como en EI1 no implica, para esos trabajadores, la posibilidad de cobrar adicionales. Así, mientras que en las empresas donde no hay delegados la ED se dirige al conjunto de trabajadores e implica el cobro de incentivos, en aquellas que sí tienen representación gremial la incorporación de ED presentan un carácter más heterogéneo entre las firmas analizadas. Es decir, la presencia sindical puede actuar como un posible limitador a la incorporación de procesos de individualización salarial a través de la ED. Para dar cuenta de las diversas conexiones que venimos desarrollando, podemos incorporar lo que nos relataban las Gerentes de Recursos Humanos de las Empresas EI1 y de EI2:

"Tenemos un nuevo sistema de evaluación que vino de Estados Unidos. A partir del proceso de evaluación de desempeño sacás el reporte de todas las notas de todos los empleados, se hacen planes de acción ya sea de capacitaciones, a los altos potenciales, o sea se tiene en cuenta las dos cosas, el potencial de la persona y el desempeño que va ligado a lo que es la nota de la evaluación de desempeño, a raíz de eso se establecen aumentos por méritos, aumentos por retención ya sea una persona que querés retener dentro de la compañía. En cambio a las personas que están dentro del convenio es muy difícil darle un aumento por mérito, ellos tienen los aumentos legales y tienen los beneficios por estar dentro del convenio. Generalmente este tipo de aumentos se aplica a personas que están fuera del convenio y que no tienen por ahí la ayuda del sindicato" (EI1).

"Sí, pero depende si están dentro de convenio o no. Cuando están por convenio nos regimos por lo que dice ese convenio. Para ellos no hay un sistema de evaluación tan estricto. Para el resto, la gente que no está convencionada, se trabaja por objetivos. La evaluación es igual para todas las filiales. Recibimos un bono que varía de acuerdo a tu perfomance individual de esa evaluación. De los objetivos propuestos en el año, si los cumpliste, si los superaste es un porcentaje mayor, si no los alcanzaste es un porcentaje menor al promedio y ese pago se hace en marzo. La gente convencionada no participa de este bono porque es para los que están fuera de convenio y cada uno se adecua al convenio que tengamos. A excepción que el convenio lo permita" (EI2)

De esta forma se pone de manifies to que en la medida que hay un CCT y una representación sindical que busca establecer lógicas colectivas en términos salariales, 
sustentado en la tradición de homogeneidad laboral de al mismo trabajo el mismo salario, allí donde no llega el CCT se comienzan a imponer formas de individualización salarial que intervienen poniendo en competencia a los trabajadores y como mecanismos de control del desempeño (Edwards y Scullion, 1982). Avanzando más en esta dirección, también aparece en las palabras de los directivos de las empresas ciertas formulaciones que ponen a la representación sindical como un hecho disruptivo a las lógicas empresarias más que defendiendo los intereses de los trabajadores, a la vez que interviene una diferenciación entre los sectores económicos:

"El proceso de evaluación es anual. A principio de año se definen los objetivos, a mitad de año se hace una revisión de los objetivos y digamos de la performance de cada uno de los empleados Todo esto se registra en la herramienta. Los objetivos a mitad de año se hace la revisión, se escribe el feedback en la herramienta, más que nada para que el empleado sepa si está bien encaminado o no, y a fin de año se hace la evaluación final. Eso te da un ranking, del cual depende el bono que vas a cobrar o no. A diferencia de la industria donde generalmente hay delegados, acá no hay delegados. Eso es un gran beneficio en relación a la industria" (OS6).

"Por suerte aqui no hay delegados, eso nos facilita un poco las cosas para poder instrumentar diferentes cosas, entre ellas la evaluación..." (ES5)
"La matriz dice que lo ideal sería evaluar en determinadas cosas a todos y después... te dicen: "Nosotros sugerimos doce aspectos a evaluar, estos seis tienen que estar, los otros seis sacalos o modificalos según convenga a tu realidad, por tu cultura o por tu operación"... Tienen esa flexibilidad. Se hace para mánager, mandos medios... El sindicato dice no podés hacerlo para diferenciar los aumentos, la paritaria es la paritaria... O para echar a alguien... Vos tenés... La evaluación de desempeño tiene tres aspectos, uno es la evaluación de los objetivos que te fijo, que son cuantitativos... Que pagan en el bono. El bono acá tiene... Todos los que están fuera de convenio tienen un bono que tiene tres componentes: uno relacionado a los resultados económicos de la compañía que es para todos igual, otro que tiene que ver con la evaluación de desempeño y por último las competencias adquiridas" (OII)

En relación a los pagos variables que conforman los salarios, se observa una mayor heterogeneidad entre las firmas, yendo desde la inexistencia de pagos variables a formas altamente individualizadas. $\mathrm{Al}$ respecto, existe un mayor pago de aspectos variables en el salario que están atados a los objetivos o productividad, ya sea de carácter colectivo o individual. En este sentido, se observa que allí donde hay presencia sindical y partes variables del salario, estos tienen un carácter colectivo, en la medida que se encuentran atados a la productividad $y$ objetivos de la empresa (EI3), en tanto que en las empresas de servicios suelen 
prevalecer los variables salariales en función de los objetivos individuales (OS5 y OS6). Otra de las formas de pagos variables se vincula con el presentismo y su mayor desarrollo se da en las empresas donde existe presencia sindical y su dinámica de pago difiere entre pagos semanales, mensuales o quincenales, lo cual se encuentra dentro del CCT (OI1, OI2 y EI2):

"Los operarios no tienen aspectos variables en sus salarios porque está todo por convenio, y los demás sí, nosotros tenemos ingenieros comerciales que tienen un variable, no por venta sino por alcanzar las metas de los objetivos a nivel trimestral, entonces por trimestre depende en qué nivel alcanzaron las metas de ese trimestre tienen un determinado porcentaje sobre el sueldo" (EI1).

"Los que están bajo convenio depende de qué dice el sindicato y el convenio en sí mismo, si tienen un plus por presentismo, un plus por antigüedad, por puntualidad, ese tipo de cosas corresponden a los empleados convencionados. Los que no estamos por convenio no recibimos cuestiones variables, sí tenemos un paquete de beneficios, no monetarios" (EI2).

Avanzando un poco más sobre las relaciones de los SPV y los sindicatos se observa que en las firmas donde la penetración sindical es menor hay un proceso de mayor individualización en los pagos variables. En las firmas del sector servicios, de 5 empresas sólo en 1 hay presencia sindical. En contraposición, existe una mayor presencia y densidad sindical en las empresas industriales.
También cabe destacar que hay una menor densidad sindical entre las firmas de Norteamérica que entre las europeas. Precisamente estas lógicas que prevalecen entre las firmas de servicios $y$ las norteamericanas se encuentran dentro de las hipótesis tradicionales, que afirman que es en este tipo de firmas donde hay menor presencia y densidad sindical.

Dentro de esta misma lógica, se observa en otros casos un proceso de "dualización" en la medida que se desarrollan procesos de individualización pero que se encuentran negociados y avalados por los sindicatos, ya sea porque se encuentra estipulado en el CCT o bien porque se halla en procesos de negociación. También se puede destacar que los procesos de individualización se desarrollan en mayor medida entre las firmas de nueva creación, es decir entre aquellas que ingresaron al mercado local durante la década de 1990, aunque este factor está condicionado por el sector de actividad y la presencia sindical.

\section{Conclusiones}

A lo largo de este artículo hemos intentando avanzar en establecer el carácter que asumen los SPV en las empresas focalizándonos en dos elementos. En primer lugar tomar como objeto de estudio a las EMN, lo cual implica no sólo ver esos procesos al interior de las empresas sino también determinar aproximadamente cómo se desenvuelvan las lógicas de funcionamiento de la gestión de la fuerza de trabajo entre las relaciones de las filiales y las casas matrices. En segundo lugar, hemos visto las relaciones laborales a través del prisma de los SPV, porque es allí donde se puede observar el juego entre los actores que intervienen y sus estrategias.

Asimismo, poder realizar estas observaciones nos permite acercarnos a las prácticas desarrolladas por las empresas. En este sentido, hace ya algunos años que las estrategias de control por parte de las empresas sobre la fuerza de trabajo se 
vienen incrementando en post de movilizar las subjetividades laborales en beneficio del capital. Este proceso, iniciado hace varios años, ha crecido en los últimos, avanzando sobre categorías de trabajadores que anteriormente quedaban al margen del alcance del conjunto de dispositivos implementados por las empresas. Un ejemplo de ellos son los procesos de individualización salarial que vienen profundizándose a través de sistemas de pagos por rendimiento, ya sea por medio de evaluaciones de desempeño o salarios variables, que ponen en competencia a los trabajadores para la obtención de mayores ingresos. De alguna manera, el trabajo presentado ha podido establecer la relación existente entre ese avance y el nivel de penetración de los sindicatos en las empresas. Por un lado, la presencia sindical limitaría el avance de las firmas sobre los procesos de individualización, pero a su vez estos condicionarían los procesos de sindicalización.

A través del análisis realizado, en primera instancia se ha mostrado que los sistemas de pago por rendimiento tienen un gran alcance entre las empresas, tanto las que se refieren a las formas de salario variable como las ligadas a las evaluaciones de desempeño. Estas últimas cumplen la doble función de buscar disciplinar a la fuerza de trabajo e individualizar los salarios. Esta individualización rompe con las lógicas colectivas que supone la realización de la misma tarea y en algunos casos se imponen por la debilidad sindical, por su ausencia o por los mecanismos utilizados por las empresas para generar las condiciones para la ausencia de representación sindical en los espacios de trabajo. En este orden se puede establecer que existe predominantemente entre las empresas analizadas una "función de gestión" en torno a los pagos variables en tanto que buscan establecer un mayor control sobre la fuerza de trabajo.

Por su parte, tomando como referencia las diferentes formas que pueden tener los SPV, se observó una mayor persistencia de aquellos vinculados al nivel de mayor individualización establecido por las evaluaciones por rendimiento de carácter individual y los correspondientes a una segunda forma, conformado por pagos vinculados a objetivos y productividad. Asimismo, se pudo establecer que hay menor presencia y densidad entre las firmas norteamericanas, si bien es en el sector servicios donde prevalecen las lógicas menos colectivas que se vinculan a los sindicatos. En este sentido, allí donde la presencia sindical es débil o inexistente se imponen pautas de individualización salarial atadas básicamente a los procesos de evaluación de desempeño, por el contrario, donde existe presencia sindical estos procesos no suelen abarcar a los trabajadores que se encuentran bajo CCT, manteniendo el sindicato, por medio de este freno, una lógica colectiva de negociación salarial, a la vez que suspende la competencia entre los mismos trabajadores. Precisamente, es importante destacar que la gerencia manifiesta como un elemento central la ausencia sindical para la incorporación de las políticas empresarias. Es así que en todas las empresas que tienen SPV por evaluación de desempeño, su alcance dependerá en gran medida de la penetración de los sindicatos en los espacios de trabajo como así también de sus estrategias.

No obstante, los SPV aparecen muchas veces negociados en los CCT con los sindicatos, lo que nos refiere a un "dualismo" en las relaciones laborales. En este sentido, nos encontramos en las empresas con elementos del "individualismo" norteamericano de las relaciones laborales tanto como con aspectos que señalan una integración entre prácticas de individualización con la negociación colectiva. De esta manera, uno de los resultados más importantes de este anális is consiste en relevar la coexistencia de las relaciones laborales históricamente tradicionales en la Argentina y las políticas de recursos humanos individualistas introducidas por las filiales de EMN, sin 
necesariamente implicar el reemplazo o siquiera la reducción del papel de los sindicatos.

Este análisis, que aún se encuentra en una primera etapa exploratoria, abre una serie de interrogantes sobre los procesos de individualización: ¿Son conscientes los trabajadores de los efectos de los procesos de individualización? ¿Cómo puede enfrentar el movimiento obrero las estrategias de individualización salarial frente a las actuales transformaciones del mundo del trabajo? ¿Cómo se podrán construir nuevas solidaridades en aquellos sectores que muestran cierta reticencia a la sindicalización?

\section{Referências}

Antenas Collderman, J. M. (2008). Los sindicatos ante la globalización. ¿Hacia que nuevas formas de solidaridad internacional? Cuadernos de relaciones laborales, 26 (1), 3555.

Aronskind, R. (2015). Intuiciones y confrontaciones. Para pensar la política económica kirchnerista. Márgenes - Revista de Economía Política, 1 (1) 15-32.

Bartram, T. \& Cregan, C. (2003). Consultative employment relations in human resource management environments with a union presence. The Journal Industrial relations, 45 (4), 539-545.

Bloom, M., Milkovich, G. \& Mitra, A. (2003). International compensation: learning from how managers respond to variations in local host contexts. International Journal of Human Reource Managment, 14, 1350-1367.

Boltanski, L. \& Chiapello, E. (2002). El nuevo espíritu del capitalismo. Madrid: Akal.
Brewster, C. (1993). Developing a "European" model of human resource management. International Journal of Human Resource Management, 4, 765-84.

Cooke, W. (2003) "The influence of industrial relations systems factors on foreign direct investment" en W. N. Cooke (ed.) Multinational Companies and Global Human Resource Strategies. Westport, CT, Quorum Books.

Cooper, R., Ellen, B., Briggs, C. \& Van de Broek, D. (2009). Anti- unionis m, Employer Strategy, and the Australian State, 1996-2005. Labor Studies Journal, 34 (3), 339-362.

Delfini, M. (2011). Relaciones laborales y "gestión de recursos humanos" en filiales de Empresas Multinacionales en Argentina. Revista Sociedad y Economía, 20, 149-170.

Delfini, M. \& Roitter, S. (2007). Las relaciones laborales en una trama automotriz argentina. Cuadernos de Relaciones Laborales, 25 (1), 195 221.

Dølvik, J. \& Nergaard, K. (2011). Variable pay, collective bargaining and trade unions: A comparison of machinery and banking companies in Norway. Economic and Industrial Democracy, 33(2), 267-293.

Dundon, T., Curran, D., Ryan, P. \& Maloney, M. (2006). Conceptualising the dynamics of employee information and consultation: Evidence from the Republic of Ireland. Industrial Relations Journal, 37, 492-512.

Dunning, J. (1994). Re-evaluating the benefits of foreign direct investment. 
Transnational corporations, 13 (1), 27-51.

Ferner, A. \& Almond, P. (2013). Performance and reward practices in foreign multinationals in the UK. Human Resource Management Journal, 23 (3), 241-261.

Flanders, A. (1970). Pay as an Incentive in Management and Unions: The Theory and Reform of Industrial Relations. London: Faber and Faber.

Flood, P. \& Toner, B. (1997). Large nonunion companies: How do they avoid a catch 22. British Journal of Industrial Relations, 35, 257-77.

Foulkes, F. (1980). Personnel Policies in Large Non-union Companies. Englewood Cliffs, N.J.: PrenticeHall.

Foulkes, F. (1981). How top non-union companies manage employees. Harvard Business Review (Sept.Oct.), 90-96.

Guest, D. (1987). Human resource management and industrial relations. Journal of Management Studies, 24, 503-521.

Gunnigle, P., Lavelle, J. \& McDonnell, A. (2007). Industrial relations in MNC: double-breasting and trade union avoidance in Ireland. Working Paper, Department of Personnel and Employment Relations, Kemmy Business School, University of Limerick, National Technological Park, Limerick, Irlanda.

Gall, G. (2009). Statutory Union Recognition Provisions as Stimulants to Employer Anti-Unionism in three Anglo-Saxon Countries. Economic and Industrial Democracy, XX (X), 1-27.
Hernández Romo, M. (2014). Alternativas para el análisis de las multinacionales. ¿Hacia dónde va el Neoinstitucionalismo? Revista Trabajo, 8 (12), 24-64.

Jacoby, S. (1985). Employing Bureaucracy Managers, Unions, and the Transformation of Work in the 20th Century. London: Lean.

Lavelle, J., Gunnigle, P. \& McDonnell, A. (2010). Patterning employee voice in multinational companies. Human relations, 63 (3), 395-418.

Léonard, E., Pulignano, V., Lamare, R. \& Edwards, T. (2014). Multinational corporations as political players. Transfer, 20 (2), 171-182.

Lepak, D. \& Snell, S. (1999). The human resource architecture: toward a theory of human capital allocation and development. Academy of Management Review, 24 (1,) 31-48.

Lewchuck, W. \& Wells, D. (2007). Transforming Worker Representation: The Magna Model in Canada and Mexico. Labour /Le travail, 60, 108-138.

Marginson, P., Arrowsmith, J. \& Gray, M. (2008). Undermining or reframing collective bargaining? Variable pay in two sectors compared. Human Resource Management Journal, 18 (4), 327-346.

Nergaard, K., Dølvik, J., Marginson, P., Arasanz Díaz, J. \& Bechter, B. (2009). Engaging with Variable Pay: A Comparative Study of the Metal Industry. European Journal of Industrial Relations; 15; 125-146.

Purcell, J. (1987). Mapping management styles in employee relations. Journal of Management Studies, 24, 533-548. 
Royle, T. (1998). Avoidance Strategies and the German System of Codetermination. International Journal of Human Resource Management, 9 (1), 1026-1047.

Sklair, L. (2003). Sociología del Sistema Global. Barcelona: Gedisa.

Tempel, A. (2001). The Cross-National Transfer of Human Resource Management Practices in German and British Multinational Companies. Mering: Rainer Hampp Verlag.

Trif, A. \& Geary, J. (2016). The purpose of variable pay schemes and trade unions. Employee Relations, 38 (2), pp.182-199, https://doi.org/10.1108/ER-01-20150004

UNCTAD (2017), World Investment Report 2008 - Transnational Corporations and the Infrastucture Challenge, Naciones Unidas, Nueva York

Van Het Kaar, R.H. and Grünell, M. (2001). Variable pay in Europe. EIR Observer, 3 (1), 1-8.

Data de submissão: 12/07/2017

Data de aceite: $\quad$ 28/10/2017 